\title{
Assistência de enfermagem em sepse neonatal
}

\author{
Nursing care in neonatal sepsis \\ Atención de enfermería en la sepsis neonatal
}

Recebido: 02/10/2021 | Revisado: 08/10/2021 | Aceito: 13/10/2021 | Publicado: 16/10/2021

Helayne Cristhina Martins de Souza
ORCID: https://orcid.org/0000-0002-4228-0560
Faculdade Integrada Carajás, Brasil
E-mail: helaynecristhina @ gmail.com
Camila Silva e Souza
ORCID: https://orcid.org/0000-0001-9865-5299
Faculdade Integrada Carajás, Brasil
E-mail: camilasilvasouza@ @outlook.com
Sttefhany Alves Leão
ORCID: https://orcid.org/0000-0002-2334-6923
Faculdade Integrada Carajás, Brasil
E-mail: sttefhanny123 @ gmail.com

\begin{abstract}
Resumo
A sepse neonatal é uma síndrome inflamatória sistêmica grave resultante de infecção com ou sem bacteremia que pode ocorrer por meio da cultura positiva nos 28 primeiros dias de vida. $\mathrm{O}$ acometimento por sepse neonatal é responsável por cinco milhões de óbitos de recém-nascidos em países subdesenvolvidos ou em desenvolvimento. Sendo assim, o objetivo do estudo é discorrer sobre a contribuição da assistência de enfermagem para redução do índice de sepse neonatal. É sabido que a enfermagem possui um papel muito importante no acompanhamento de crianças em UTI neonatal, a prática embasada em conhecimentos teórico-metodológico além da Sistematização da Assistência de Enfermagem-SAE que é uma metodologia que confere segurança à prática de enfermagem. O estudo buscou apresentar uma revisão de literatura sobre a assistência da enfermagem em atendimento a criança em UTI que apresente sepse neonatal, reforçando a importância do diagnóstico precoce e a intervenção do tratamento. A pesquisa apresenta o conceito clínico de sepse neonatal, suas características clínicas e os cuidados de enfermagem para o cuidado com o recém-nascido com essa infecção. Trata-se de uma pesquisa bibliográfica de caráter descritivo com abordagem qualitativa sendo utilizado artigos científicos publicados nas bases de dados, Lilacs, Scielo, Medline entre outras revistas e as normativas legais do Ministério da Saúde que abordam a temática. O estudo evidencia a importância do cuidado preventivo na assistência ao recém-nascido, adotando medidas preventivas e reconhecendo os sinais precocemente para que se trate a sepse neonatal revertendo assim as consequências da infecção.
\end{abstract}

Palavras-chave: Sepse neonatal; Enfermagem; Cuidados; Diagnóstico.

\begin{abstract}
Neonatal sepsis is a severe systemic inflammatory syndrome resulting from infection with or without bacteremia that can occur through positive culture in the first 28 days of life. The involvement of neonatal sepsis is responsible for five million deaths of newborns in underdeveloped or developing countries. Thus, the objective of the study is to discuss the contribution of nursing care to reduce the rate of neonatal sepsis. It is known that nursing has a very important role in monitoring children in the NICU, a practice based on theoretical-methodological knowledge in addition to the Systematization of Nursing Care-SAE, which is a methodology that provides security to nursing practice. The study sought to present a literature review on nursing care in assisting children in the ICU with neonatal sepsis, reinforcing the importance of early diagnosis and treatment intervention. The research presents the clinical concept of neonatal sepsis, its clinical characteristics and nursing care for the care of newborns with this infection. This is a bibliographic research of descriptive character with a qualitative approach using scientific articles published in the databases, Lilacs, Scielo, Medline, among other journals and the legal regulations of the Ministry of Health that address the subject. The study highlights the importance of preventive care in newborn care, adopting preventive measures and recognizing early signs to treat neonatal sepsis, thus reversing the consequences of the infection.
\end{abstract}

Keywords: Neonatal sepsis; Nursing; Care; Diagnosis.

\section{Resumen}

La sepsis neonatal es un síndrome inflamatorio sistémico grave resultante de una infección con bacteriemia o sin ella que puede ocurrir por cultivo positivo en los primeros 28 días de vida. La participación de la sepsis neonatal es responsable de cinco millones de muertes de recién nacidos en países subdesarrollados o en desarrollo. Así, el objetivo del estudio es discutir la contribución de los cuidados de enfermería para reducir la tasa de sepsis neonatal. Se sabe que 
la enfermería tiene un papel muy importante en el seguimiento de los niños en la UCIN, práctica basada en el conocimiento teórico-metodológico además de la Sistematización de la Atención de Enfermería-SAE, que es una metodología que brinda seguridad a la práctica de enfermería. El estudio buscó presentar una revisión de la literatura sobre el cuidado de enfermería en la asistencia a los niños en la UCI con sepsis neonatal, reforzando la importancia del diagnóstico temprano y la intervención del tratamiento. La investigación presenta el concepto clínico de sepsis neonatal, sus características clínicas y el cuidado de enfermería para el cuidado del recién nacido con esta infección. Se trata de una investigación bibliográfica de carácter descriptivo con enfoque cualitativo utilizando artículos científicos publicados en las bases de datos, Lilacs, Scielo, Medline, entre otras revistas y la normativa legal del Ministerio de Salud que abordan el tema. El estudio destaca la importancia de la atención preventiva en el cuidado del recién nacido, adoptando medidas preventivas y reconociendo los primeros signos para tratar la sepsis neonatal, revirtiendo así las consecuencias de la infección.

Palabras clave: Sepsis neonatal; Enfermería; Cuidado; Diagnóstico.

\section{Introdução}

O nascimento prematuro está relacionado a um número elevado de mortalidade neonatal, isso porque, são mais suscetíveis a doenças graves. De acordo com estudo de Silva et al. (2015) no Brasil a taxa de prematuridade é de 9,2\% e 60\% da mortalidade infantil ocorre nesse período de vida da criança.

Em conformidade Alves et al. (2016) afirma que a ocorrência de sepse neonatal é responsável por cinco milhões de óbitos de recém-nascidos, sendo que em países subdesenvolvidos ou em desenvolvimento. Os grupos de recém-nascidos mais susceptíveis são geralmente aqueles que são submetidos a procedimentos invasivos durante internações em Unidades de Terapia Intensiva Neonatal-UTIN.

A UTIN consiste em local definido para assistência de recém-nascidos graves com idade de 0 a 28 dias, sendo fundamental a utilização de recursos tecnológicos e humanos para assistência. O cuidado nesse ambiente requer profissionais com conhecimentos técnicos e tecnológicos para garantir ao RN atendimento de qualidade com o intuito de manutenção da vida (Rosa et al., 2021).

A Sepse neonatal é uma síndrome de resposta inflamatória sistêmica resultante da suspeita ou afirmação de infecção com ou sem bacteremia e que pode ser documentada por meio da cultura positiva nos 28 primeiros dias de vida. Desta maneira, pode ser classificada como de início precoce ou tardio, em que a sepse neonatal precoce parece em torno de até $7^{\circ}$ dia de vida, normalmente nas primeiras 24 h de vida. Porem em pré termos aparece até o $3^{\circ}$ dia de vida. A sepse neonatal tardia ocorre após o $7^{\circ}$ dia de vida (Hammad; Zainab, 2018).

Segundo Silva et al. (2015) a sepse neonatal pode ser classificada em precoce ou tardia. A sepse precoce ocorre nos três primeiros dias de vida do recém-nascido-RN e geralmente está relacionado com fatores de riscos materno, isso porque os agentes bacterianos estão presentes no canal do parto. Já a sepse tardia se apresenta no quanto dia de vida do RN em atendimento de UTI neonatal e está relacionada com os fatores externos, ou seja, de origem hospitalar.

A enfermagem tem um papel importantíssimo nesse processo, isso porque a adoção de protocolos de reconhecimento precoce e a intervenção do tratamento padronizado são estratégias que reduzem a mortalidade infantil em decorrência da sepse neonatal. Estudos evidenciam a importância do diagnóstico precoce visto que na maioria dos casos só acontecem tardiamente o que agrava o quadro do RN (Bassi, Sampaio, 2018).

Sendo assim, é de suma relevância que a equipe de Enfermagem que são os profissionais que prestam assistência 24 h, estejam capacitados em suas ações, pois se não realizarem os procedimentos de forma correta evitando falhas podem contribuir para elevação da gravidade da sepse podendo levar ao óbito do RN (Nascimento; Silva, 2014).

Os profissionais de enfermagem são os que consegue observar de início as alterações no quadro clinico do recémnascido, estando sempre atentos aos sinais e sintomas, por isso se faz importante o trabalho do profissional de enfermagem no diagnóstico e nas intervenções necessárias aos recém-nascidos, desta forma, o enfermeiro e o responsável por delegar as tomadas de decisões diante da situação exposta (Souza et al., 2020). 
Segundo Terry e Weaver (2013) os enfermeiros que atuam em UTI prestam serviços norteados por padrões de cuidados, os quais subsidiam a esquematização para qualidade da assistência prestada, bem como um guia de como deve ser os cuidados ao paciente em estado crítico. Nesse aspecto, a implantação da Sistematização da Assistência de Enfermagem-SAE no acompanhamento de crianças em UTI neonatal confere maior segurança ao RN, melhora a qualidade da assistência e propicia maior autonomia aos profissionais de enfermagem.

A SAE é uma metodologia científica na qual a enfermagem dispõe para executar seus conhecimentos técnico-científicos e humanos na assistência de um paciente, possibilitando qualidade e segurança ao assistido, além de subsidiar a prática de enfermagem de forma consciente para tomada de decisão e contribuindo para credibilidade profissional. Com a SAE o atendimento em UTIN será prestado de forma humanizada, evitando os efeitos da hospitalização e atendendo as peculiaridades patológicas de forma segura (Tanure, Pinheiro, 2017).

Sendo assim, o estudo se justifica por entender a necessidade de adquirir conhecimentos sobre a Sepse Neonatal, isso tanto para os profissionais que já atuam na área quanto à acadêmicos em formação. A pesquisa demonstrará dados significativos para aperfeiçoamento da assistência de Enfermagem em relação a prestação de cuidados aos pacientes Recém-nascidos em Unidades de Terapia Intensiva.

\section{Metodologia}

\subsection{Tipo de estudo}

Trata-se de uma revisão narrativa da literatura realizada por meio de textos apanhados em pesquisas em sítios da rede mundial de computadores, com caráter descritivo na qual descreverá os atributos e condições da definição das variáveis, sendo o mais preciso possível. Para isso, será usada a abordagem qualitativa sintetizando os dados coletados sobre a Sepse Neonatal enfocando principalmente a assistência da enfermagem. O estudo tem como base metodológica os autores Ludke e Andrade (2013).

\subsection{Coleta de dados}

Para a coleta dos dados será realizado pesquisa de artigos publicados nas bases de dados Biblioteca Virtual em Saúde (BVS), Literatura Latino-Americana e do Caribe em Ciências da Saúde (LILACS) e Scientific Eletronic Library Online (SciELO). Será realizado busca nos sites da Organização Mundial da Saúde (OMS) e Ministério da Saúde, livros e revistas que abordam a temática versada.

Os descritores em Ciências da Saúde (DeCS) utilizados na elaboração do estudo serão: Cuidados de Enfermagem; Recém-Nascido; Sepse Neonatal. Inicialmente o filtro de pesquisa apresentou 26 artigos, mas após a seleção ficaram definidos o uso de 22 artigos publicados na qual subsidiaram a referida pesquisa.

\subsection{Critérios de inclusão e exclusão dos artigos}

Os artigos selecionados foram publicados nos anos de 2012 a 2020 em português e inglês que abordam a Sepse neonatal e a assistência de enfermagem, apenas os estudos que estão disponibilizados na íntegra. Serão excluídos os artigos que discorrem sobre a prática de outros profissionais bem como os publicados anterior ao ano de 2012 como exemplifica a tabela abaixo. 
Tabela 1: Critério de inclusão e exclusão de artigos.

\begin{tabular}{|c|c|}
\hline INCLUSÃO & EXCLUSÃO \\
\hline Artigos publicados de 2012 a 2021 & Artigos anteriores a 2012 \\
\hline Estudos em Língua Portuguesa e inglesa & Estudos em Língua espanhol \\
\hline Que abordam sobre a sepse neonatal & $\begin{array}{l}\text { Que abordam outras situações que não seja a } \\
\text { sepse neonatal }\end{array}$ \\
\hline $\begin{array}{l}\text { Que discorrem sobre a prática de enfermagem em } \\
\text { UTIN }\end{array}$ & Que discorrem sobre a prática fora da UTIN \\
\hline Textos completos & Texto incompletos \\
\hline
\end{tabular}

Fonte: Autoras (2021).

\section{Resultados e discussão}

\subsection{Sepse neonatal}

A sepse neonatal consiste em uma infecção bacteriana, viral ou fúngica invasiva que acomete o RN em fase neonatal, e está associada a várias alterações hemodinâmicas e outras manifestações clinicas. Trata-se de uma síndrome clínica caracterizada por múltiplas manifestações sistemáticas decorrentes da invasão e multiplicação bacteriana na corrente sanguínea (Alves et al., 2016).

A contaminação pode ocorrer na vida intrauterina e durante o nascimento, o feto e o recém-nascido podem ser colonizados por microrganismos no trajeto do canal de parto com a flora do trato genital materno ou pela via transplacentária. Esses micro-organismos alojam-se em determinado órgão ou vasos sanguíneos formando um processo inflamatório caracterizando a sepse, que não havendo diagnóstico precoce pode evoluir para estado grave ou até mesmo levar a óbito (Silveira; Procianoy, 2012; Bassi, Sampaio, 2018).

Segundo Bassi e Sampaio (2018) a sepse é uma doença de evolução rápida superando até mesmo o infarto do miocárdio e alguns tipos cancerígenos. É uma doença que se apresenta de forma heterogênea com variações clinicas, possuindo malignidade e sintomas desde o início de sua instalação no organismo. No entanto, alguns sintomas são despercebidos ou confundidos pela equipe de atendimento, portanto, uma atenção mediada por conhecimentos técnicos é fundamental para o diagnóstico precoce e intervenção.

Os principais sinais e sintomas apresentados em RN com sepse são: taquicardia >90 bpm (aumento da frequência cardíaca), temperatura de $38^{\circ} \mathrm{C}$ ou $<36^{\circ} \mathrm{C}$ e taquipnéia $>20 \mathrm{ipm}$ (aumento da frequência respiratória), contagem de leucócitos $>12.000$ ou < que 4.000 e acúmulo de ácido lático no organismo. O RN apresentando dois ou mais desses sinais e sintomas há suspeita de sepse e pode ser iniciado o tratamento precoce com a prescrição de antibióticos e a solicitação de exames laboratoriais para comprovação do diagnóstico. Importante salientar que estudos afirma a importância de se realizar intervenções antes das 6h após os primeiros sintomas, evitando assim, o agravamento da doença. Em consonância a recomendação no 6/2014 do Conselho Federal de Medicina determina que todas UTIN devem segui o protocolo para reconhecimento precocemente da sepse, capacitando para isso, sua esquipe multiprofissional (Oliveira et al., 2016).

O diagnóstico precoce não é algo simples, isso porque não existe teste diagnóstico definitivo e os exames laboratoriais de culturas de líquidos biológicos e de secreções não apresentam resultados positivos. Sendo assim, o olhar e atenção do profissional diante dos sintomas e sinais são fundamentais para tomada de decisão. Daí a importância de formação continuada à equipe multiprofissional para realização de diagnóstico precoce (Oliveira et al., 2016).

Para Oliveira et al. (2016) os sinais e sintomas não são precisos e específicos, além de que no início apresentam-se de forma silenciosa o que pode confundir com o quadro clínico decorrente da prematuridade. Nesse sentido, é percebível que a maioria das crianças tratadas por suspeita de sepse não há confirmação exata de infecção apenas a suspeita clinica presumida. 
No entanto, a investigação dos riscos para contaminação de sepse neonatal é fundamental para adoção de medidas pela equipe multiprofissional precocemente.

O termo sepse não se restringe apenas à síndrome inflamatória sistêmica secundaria a infecção bacteriana, mas aquela resultante de qualquer microrganismo e/ou seus produtos (toxinas). A sepse neonatal também pode ser descrita como precoce ou tardia, que será determinado pelo período de tempo, ou seja, as manifestações clinicas de início precoce geralmente ocorrem dentro das primeiras $72 \mathrm{~h}$ da vida (Freitas et al., 2016).

A sepse neonatal de início precoce ocorre geralmente os organismos adquiridos intraparto, isso significa que muitas lactentes têm sintomas nas primeiras $6 \mathrm{~h}$ do nascimento. Geralmente evolui com sinais de instabilidade hemodinâmica: perfusão periférica inadequada, alteração de amplitude de pulsos periféricos, hipotensão, caracterizando o quadro de choque séptico (Freitas et al, 2016).

Conforme o estudo de Silva et al. (2015) alguns fatores perinatais maternos e obstétricos fazem com que ocorra o aumento do índice de risco de sepse neonatal de início precoce como:

Quadro 1: Fatores que contribuem para o aumento do índice de risco de sepse neonatal.

\begin{tabular}{|l|l|}
\hline \multirow{7}{*}{ Aumento do índice de risco de sepse neonatal } & $\begin{array}{l}\text { Ruptura prematura das membranas que podem ocorrer 18h antes do } \\
\text { parto. }\end{array}$ \\
\cline { 2 - 3 } & $\begin{array}{l}\text { Corioamnionite materna que se manifesta com febre materna um } \\
\text { pouco antes ou até mesmo durante o parto com leucocitose materna, } \\
\text { taquicardia, sensibilidade uterina e com o líquido amniótico fétido. }\end{array}$ \\
\cline { 2 - 3 } & Parto prematuro. \\
\cline { 2 - 3 } & $\begin{array}{l}\text { Desta forma, a vida ascendente da infecção pode ajudar a explicar o } \\
\text { fenômeno de sepse neonatal, como a alta incidência de ruptura } \\
\text { prematura da membrana nas infecções neonatais, o significado da } \\
\text { inflamação amnionite que está mais frequente a sepse neonatal do } \\
\text { que a placentite central, e também o risco elevado de infecção do } \\
\text { gêmeo que estiver mais perto do canal de parto e as características } \\
\text { bacteriológicas da sepse neonatal de início precoce, que são reflexos } \\
\text { da flora da cavidade vaginal materna. }\end{array}$ \\
\hline
\end{tabular}

Fonte: Silva et al. (2015) adaptação das autoras.

A maioria dos casos de sepse neonatal precoce são ocasionados por estreptococos do grupo B e organismos Gramnegativos entéricos (Escherichia coli). Culturas realizadas por meio de material retal e vaginal de gestantes revelam na maioria dos casos taxas elevadas de colonização de estreptococos do grupo B de até $35 \%$, ou seja, $35 \%$ dos recém-nascidos ficam colonizados com tal microrganismo (Santos et al., 2014).

O estudo de Procianoy e Silveira (2020) enseja que o diagnóstico da sepse precoce é dificultoso o que acarreta no uso excessivo de antibióticos. Nesse aspecto, o profissional de enfermagem precisa estar atendo aos sinais clínicos e utilizar estratégias como a observação atenta e frequente dos sinais clínicos evitando assim, o uso exacerbado de antibióticos e exames laboratoriais. Preocupados com o uso excessivo de medicamentos e exames o grupo Kaiser Permanent Northern California desenvolveu uma calculadora para RN com idade gestacional igual ou maior que 34 semanas, na qual leva em atenção a idade gestacional, o tempo de bolsa rota, temperatura da mãe, presença por Streptococcus agalactiae e uso neonatal precoce.

Quando o nascimento do RN pré-termo ocorre depois do parto espontâneo, ou há ruptura prolongada de membrana amniótica ou ainda presença de corioamnionite o risco de sepse precoce é elevado. Em parto cesariana, sem bolsa rota e trabalho de parto esse risco é considerado baixo. Como exemplo pode ser citado cesarianas em pacientes pré-eclâmpsia que tiveram de ter a sua gestação interrompida por razões obstétricas (Procianoy, Silveira, 2020).

Em relação a sepse neonatal tardia e adquirida em sua grande maioria e acometida do meio ambiente externo, principalmente de infecções adquiridas em hospitais. Os Estafilococos correspondem por 30 a $60 \%$ dos casos de início tardio 
que estão localizados pelo mal-uso e manipulação inadequada de instrumentos intravasculares em particular os acessos vasculares centrais. E Escherichia coli são reconhecidas em casos de sepses em especial os lactentes com peso extremante baixos. Outra bactéria que também ocasiona a sepse neonatal são as Enterobacter cloacae, podem ser encontradas no sangue o no líquor, e são causadas por alimentos contaminados. Equipamentos respiratórios contaminados são suspeitos de surtos de pneumonia ou sepse por Pseudomonas aeruginosa adquiridas em hospitais (Santos et al., 2014).

O estudo de Nascimento e Silva (2014) afirma que no início tardio os fatores de riscos relacionados são:

- O parto pré-termo

- Uso prolongado de cateter intravascular

- Doenças associadas que poder ser ocasionadas por procedimentos invasivos.

- Exposição aos antibióticos

- Hospitalização prolongada

- Equipamentos ou soluções intravenosas ou enterais contaminadas.

O estudo de Procianoy, Silveira (2020) destacam algumas medidas para prevenção da sepse neonatal:

Quadro 2: Medidas para prevenção da sepse neonatal tardia.

\begin{tabular}{|l|l|}
\hline \multirow{5}{*}{ Medidas indicadas para prevenção da sepse neonatal tardia } & $\begin{array}{l}\text { Lavagem das mãos ou uso de álcool em gel: essa medida é a mais } \\
\text { eficaz para prevenir infecções. A OMS destaca os cinco momentos } \\
\text { de higienização de mão: 1. antes do contato com o paciente; } 2 \text {. antes } \\
\text { do procedimento; 3. após risco de exposição a fluidos biológicos; } 4 . \\
\text { após contato com paciente; 5. após contato com áreas próximas ao } \\
\text { paciente. }\end{array}$ \\
$\begin{array}{ll}\text { Bundles apropriados e bem definidos de cuidados com cateteres } \\
\text { intravasculares centrais e tubos endotraqueais que sejam } \\
\text { rigorosamente seguidos com o objetivo de diminuir a contaminação. }\end{array}$ \\
$\begin{array}{l}\text { Alimentação enteral trófica: o início precoce da alimentação trófica } \\
\text { contribui para a maturidade intestinal, prevenindo a atrofia das } \\
\text { vilosidades e diminuindo também a translocação bacteriana e a } \\
\text { invasão bacteriana através da mucosa intestinal. }\end{array}$ \\
\hline $\begin{array}{l}\text { Uso de leite materno: o leite materno é um alimento rico em IgA e } \\
\text { oligossacárides que lhe conferem propriedades anti-infecciosas. O } \\
\text { uso exclusivo do leite materno determina uma microbiota intestinal } \\
\text { com maior diversidade, o que propicia menor probabilidade de } \\
\text { infecções. }\end{array}$ \\
\hline $\begin{array}{l}\text { Probióticos: embora existam estudos que evidenciam a utilidade de } \\
\text { probióticos na prevenção da sepse neonatal tardia, também existem } \\
\text { estudos que discutem sobre seu uso rotineiro. No entanto, não pode } \\
\text { haver generalização. }\end{array}$ \\
\hline $\begin{array}{l}\text { Lactoferrina: há divergência em estudos quanto ao papel da } \\
\text { lactoferrina como fator protetor de sepse neonatal tardia. Porém, } \\
\text { indicação do uso de lactoferrina como medida preventiva de sepse } \\
\text { neonatal tardia ainda está em avaliação }\end{array}$ \\
\hline
\end{tabular}

Fonte: Procianoy, Silveira, (2020, p. 84), adaptação das autoras.

O acompanhamento a pacientes com sepse neonatal é um grande desafio para o profissional de enfermagem, isso porque o seu diagnóstico requer conhecimentos clínicos e observação continua, saber reconhecer os sinais e sintomas fazendo uma relação com os fatores de risco é imprescindível para um diagnóstico e intervenção precoce (Dortas et al., 2019) 


\subsection{A assistência de enfermagem na assistência a RN com sepse neonatal}

A enfermagem tem um papel importantíssimo nos cuidados ao paciente em tratamento em período de internação hospitalar, isso porque é de responsabilidade desse profissional o acompanhamento a ministração medicamentosa prescrita pelo médico, bem como a observação à evolução do paciente. O processo saúde-doença é um dos pontos centrais para enfermagem que busca promover a saúde, cuidando para que as pessoas possam ter, tanto quanto possível, uma boa qualidade de vida, mesmo quando as limitações se estabelecem. Para essa relação especial com os clientes, é necessário o aprendizado do uso dos instrumentos e das tecnologias para o cuidado que compõe a formação profissional de enfermagem (Westphalen, Carraro, 2011).

Sendo assim, a formação profissional é imprescindível para prática de enfermagem, no entanto, a relação entre conhecimento e competência fica, dessa forma, configurada como uma articulação importante. No entanto, isso não assegura uma ação competente, pois, segundo Neri (2012) compete ao profissional saber articular, interagir, mobilizar conceitos (das mais diversas áreas do conhecimento) e ter capacidade de unir à ação um comportamento ético e moral condizente com os princípios da cidadania.

A assistência ao recém-nascido passou por grandes transformações havendo variações na organização do trabalho decorrentes dos diferentes contextos socioeconômicos e políticos. Na história social, a assistência à criança é associada ao contexto da organização da sociedade, enfocando os determinantes e necessidades nas mudanças ocorridas (Souza et al., 2020).

Assistência complexa e adequada realizada por uma equipe multidisciplinar, destacando-se a de enfermagem como essencial pelo cuidado direto e contínuo que presta ao neonato. Este cuidado inicia-se a partir da comunicação entre os profissionais, no sentido de serem providenciados o preparo do leito, a recepção do RN, a instalação de equipamentos e a realização de cuidados necessários para a sua sobrevivência com o mínimo de sequela possível (Viana et al., 2017).

A enfermagem é o profissional mais presente na assistência e cuidados relacionados ao paciente, sendo assim, é de suma importância relacionar o seu papel na identificação e cuidado ao paciente séptico, atuando junto a equipe multiprofissional no diagnóstico e tratamento precoce e consequente diminuição da morbimortalidade (Viana et al., 2017).

A identificação precocemente dos sinais e sintomas de sepse pelo enfermeiro contribui de fato para redução e desfechos ruins e isso pode garantir uma melhor qualidade assistencial. Principalmente quando se fala de um paciente critico, onde requer que o profissional de enfermagem tenha conhecimentos específicos e especializados de modo que atenda diferentes necessidades e graus de cuidados no que se refere a identificação de sinais clínicos da sepse neonatal (Alves et al., 2018).

Sendo assim, Souza et al. (2018) enfatiza que a busca por conhecimento e atualizações constantes pelo enfermeiro e sua equipe, possibilita o desenvolvimento de ações ágeis e seguras, com resultados efetivos na qualidade assistencial do paciente. No que diz respeito a sepse neonatal a formação continuada é imprescindível para a identificação precoce dos sinais e sintomas o que possibilita tratamento em tempo hábil evitando assim complicações ou avanço da doença.

Entende-se que o ato de diagnosticar é um processo que exige aplicação de conhecimentos para identificar os problemas de saúde reais e potenciais, este processo exige o desenvolvimento de conhecimentos, habilidades e, consequentemente, experiência em vários ambientes clínicos (Souza et al., 2018).

E os cuidados de melhoria andam agregados a mudar aquilo que impede a continuidade da vida. Os cuidados quotidianos estão associados aos hábitos de vida, costumes e crenças, são os cuidados com a alimentação, eliminações, higiene e contribuem para o desenvolvimento do ser, mantendo a imagem do corpo. Neste contexto, o cuidado da enfermagem revela um marcante destaque atuando como componente de um processo no qual o melhor de cuidar é ir além dos cuidados técnicos e ser capaz de escutar, conversar, ter flexibilidade para com o outro e para consigo mesmo (Santos et al., 2014).

O cuidar do RN requer integralmente o cuidado deste estabelecendo uma conexão de dependência, posto que o cuidado ao neonato é diferenciado, considerando que suas necessidades precisam ser percebidas e atendidas (Silva et al., 2015). 
Conforme alude o estudo de Silva et al (2015) uma forma pratica e eficiente para uma adequada assistência de enfermagem estão relacionadas as medidas profiláticas uma vez que estas são consideradas práticas de prevenção, tais como:

- Higienização das mãos: ponto referencial na profilaxia das infecções neonatal. Pode ser considerada umas das práticas mais relevantes de prevenção. Oferecer e facilitar esta pratica no âmbito hospitalar por todos os da assistência de saúde da equipe neonatal.

- Medidas de prevenção e bloqueio contra a disseminação de microrganismos multirresistentes por meio do uso de EPI's Equipamentos de Proteção Individual e artigos de precauções de contato.

- Cuidados com cateteres deve se ter uma atenção redobrada, pois esses dispositivos são implantados no paciente de forma invasiva, desta maneira o enfermeiro deve estimular formação de equipes de implantação e manutenção destes dispositivos, além disso, a utilização por meio de protocolos de manuseio e cuidado por todos os membros da equipe da unidade.

Em suma Mota et al. (2013) elucida que a lavagem das mãos é uma prática de assepsia simples que continua sendo a principal forma de prevenir e controlar as infecções, sem ônus significativos para as instituições, além de gerar benefícios extensíveis àqueles envolvidos no processo de cuidado, devendo configurar-se como um hábito que todos os profissionais de saúde devem realizar antes e depois de qualquer procedimento, seja ele invasivo ou não.

Portanto, o conhecimento dos profissionais de enfermagem sobre a sepse possui algumas deficiências que podem ser ajustadas, pois infelizmente ainda existe falhas principalmente em especialização relacionadas a sepse neonatal. $\mathrm{O}$ reconhecimento precoce e o tema primordial para um bom diagnostico e para o tratamento além do prognostico futuro desse paciente. (Freitas et al., 2016).

Vale ressaltar que a inserção da sepse na grade curricular dos cursos de graduação e técnica na área da saúde e algo que se deve ser disseminado para os futuros profissionais de saúde. Enfermeiros e técnicos de enfermagem, são profissionais que estão na linha de frente do cuidado, devendo, portanto, estarem capacitados reconhecendo as deficiências, detectados sinais e sintomas, além de dar a assistência necessária ao paciente neonato (Oliveira et al., 2016).

\subsection{A SAE enquanto instrumento de segurança no acompanhamento de pacientes com sepse neonatal}

Para realização das atividades de cuidado é imprescindível instrumental que operacionaliza o cuidar, nesse sentido, a Sistematização da Assistência de Enfermagem (SAE), possibilita que a enfermagem identifique as necessidades básicas do paciente assistido em UTIN, por meio do processo de enfermagem, elaborando um plano de cuidados.

Segundo Reppetto e Souza (2015) com a SAE a enfermagem "[...] consegue prestar uma assistência planejada fundamentada em conhecimentos, viabilizando um cuidado objetivo e individualizado". As informações exigidas na SAE fornecem ao enfermeiro pressupostos que identificaram os problemas de saúde do paciente, subsidiando o planejamento do acompanhamento desse paciente.

De acordo com Bittar et al. (2016, p. 80): "[...] incorporar a SAE é uma forma de tornar a enfermagem mais científica, promovendo um cuidar de enfermagem humanizado, contínuo, mais justo e com qualidade para o paciente/cliente". Nesse aspecto, a construção da SAE requer do profissional de enfermagem conhecimento sobre os objetivos do atendimento na UTIN e de assistências a RN com sepse neonatal.

A primeira parte do processo da SAE faz-se necessário discriminar a identificação do paciente, dados estes imprescindíveis para visualização socioeconômica e clínica do assistido, isso possibilita um planejamento de acompanhamento 
baseado na realidade do caso. As etapas a seguir retratam as condições de saúde e as doenças que acometem o RN, essas informações servirão para acompanhamento e monitoramento da equipe multiprofissional (Tanure, Pinheiro, 2017).

Nesse sentido, Souza et al. (2015), conceitua a SAE discorrendo sua importância na instrumentalização de enfermagem "Constitui, portanto, um modelo de processo de trabalho que sistematiza a assistência e direciona o cuidado integral e individualizado, garantindo segurança ao usuário do sistema de saúde e aos profissionais envolvidos com a sua assistência". Sendo assim, a sistematização tem como objetivo dá segurança ao usuário através de dados precisos e verdadeiros que irá nortear o seu tratamento.

A Resolução do COFEN n 358/2009 determina enquanto obrigatoriedade a aplicação da SAE na prática cotidiana da enfermagem em suas múltiplas faces de atuação, visto que esse instrumento tem base em estratégias científicas que são planejadas para conhecimento, identificação e intervenção profissional. Portanto, o preenchimento completo e adequado da SAE irá contribuir significativamente para o monitoramento e a tomada de decisão da equipe multiprofissional, a informação referente ao quadro de saúde do paciente possibilitará um atendimento de qualidade ao $\mathrm{RN}$ assistido.

Segundo Souza et al (2015), mesmo com determinação de obrigatoriedade pelo COFEN, ainda é um grande desafio a aplicabilidade da SAE nas unidades de saúde, pois apesar de conhecer teoricamente sua necessidade a realidade dentro do sistema de saúde diverge. Dentre as principais dificuldades de implantação da SAE, os estudos apontam dois: institucional, que é a ausência do instrumento e a falta de profissionais diante da demanda de pacientes.

Os dados da pesquisa de Silva et al. (2015) sintetizam esse entendimento:

Quadro 3: Dificuldades para utilização da SAE.

\begin{tabular}{|l|c|}
\hline Dificuldade & $\mathrm{N}^{\mathbf{0}}$ \\
\hline Não implantação & 34 \\
\hline Falta de profissionais & 19 \\
\hline Alta demanda de pacientes & 11 \\
\hline Falta de tempo / sobrecarga do enfermeiro & 08 \\
\hline Falta de capacitação e treinamento & 03 \\
\hline
\end{tabular}

Fonte: Silva et al (2015), p. 7106.

O quadro evidencia as maiores dificuldades citadas para implantação da SAE dentre elas a não implantação que diz respeito a resistência de alguns profissionais em utilizar o instrumento e a outra diz respeito a ausência de profissionais suficientes para demanda nas unidades de saúde, o que compromete o trabalhado com êxito do profissional.

Para Barbosa et al. (2015) a utilização da SAE:

[...] eleva a qualidade da assistência de enfermagem, beneficiando tanto o paciente, através de um atendimento individualizado, quanto ao serviço do enfermeiro, proporcionando meios para organizar as informações e os dados dos clientes, para analisar e interpretar esses dados, para cuidar e avaliar os resultados do processo de cuidar de forma segura, dinâmica e competente, e que com a ausência da SAE, ficaria menos visível saber como o paciente está se recuperando, pois não haveria informação do seu estado de saúde físico e mental em registros (Barbosa et al., 2015, p. $14)$.

Nesse entendimento, a instrumentalização é imprescindível para a qualidade dos serviços prestados pela enfermagem potencializando os cuidados em saúde. Os dados contidos na SAE são elementos necessários para tomada de decisão na evolução do paciente com sepse neonatal. 
Comungando com esse entendimento o estudo de Oliveira (2014) afirma que "ao utilizar a SAE, o enfermeiro é capaz de proporcionar maior segurança ao paciente e o possibilita expressar suas ansiedades, medos e angústias, o que acarreta na oferta de um cuidado integral e individualizado". No entanto, para utilização desse instrumento de forma eficiente é fundamental que o profissional conheça todas as etapas da SAE, bem como a importância desse instrumento para melhoria do serviço prestado.

Nesse aspecto, o conhecimento da SAE deve ser desde academia e permanecer em formação continuada, assim sendo, o estudo de Guedes (2012) aborda que a percepção de alunos e educadores sobre o instrumento da SAE requer aprofundamento das etapas, bem como o seu reconhecimento enquanto instrumento de trabalho de enfermeiros.

Para os autores Brito e Barcelos (2017):

[...] o conhecimento inadequado ou insuficiente dos profissionais de enfermagem acerca do SAE ocasiona uma dificuldade na implantação, adesão e realização desta nos serviços de saúde. Observando-se a necessidade da educação permanente nos serviços de saúde discutindo a SAE no dia a dia da assistência e apontando para o seu desenvolvimento no exercício profissional (Brito Barcelos, 2017, p.29).

É inegável a importância do conhecimento adequado para implantação e utilização da SAE, conhecer suas etapas, sua funcionalidade e aplicabilidade. Nas UTIN a sistematização da assistência de enfermagem proporcionará uma assistência de qualidade, desde que seja utilizado por profissional capacitado.

A SAE proporciona aos profissionais de enfermagem autonomia para elaboração do planejamento para acompanhamento do paciente com sepse neonatal. Garante, também, organização do serviço da equipe multiprofissional dinamizando a assistência. Portanto, a sistematização organizará o trabalho do enfermeiro na UTIN, onde ele poderá trabalhar o processo de enfermagem e educação continuada, visto que Sae=Processo+Educação continuada do cuidador e do paciente.

\section{Conclusão}

O estudo discorreu sobre a sepse neonatal abordando a importância da enfermagem para o diagnóstico e intervenção precoce. Nesse sentido, vale frisar que a pesquisa alcançou os objetivos propostos inicialmente, visto que ficou evidente que o enfermeiro tem um papel importantíssimo na redução de casos graves de sepse neonatal.

A sepse é considerada uma doença com alta letalidade e que o maior instrumento para reduzir esse índice é o diagnóstico precoce, o que não é algo simples, mas com conhecimentos e formação continuada é possível aprimora o cuidado clínico para uma percepção mais eficiente dos sinais e sintomas.

A formação inicial e continuada abordando os cuidados em RN com sepse neonatal contribuem realização de processos sistematizados de forma eficiente e precisa, evitando assim, intervenção tardia. A SAE constitui-se um importante instrumento para coleta de informações e tomada de decisão, portanto, a utilização desse instrumento pelo profissional de enfermagem é uma estratégia significativa na redução de morbi-mortalidade de RN.

A temática é de extrema importância para o profissional de enfermagem, sendo assim, sugere-se a ampliação dos estudos principalmente no quesito de estatísticas comparativas, no qual possibilita vislumbrar o cuidado da enfermagem e sua eficácia no tratamento precoce de sepse neonatal. Como a sepse neonatal é difícil de ser diagnosticada e com isso há uma medicamentalização desnecessária, quanto mais houver estudos que discorrem sobre o tema, melhor para a atuação profissional.

Em suma, a capacitação profissional da equipe de enfermagem e a padronização de condutas aliadas ao replanejamento, são fundamentais para uma prática segura e ética. 


\section{Referências}

Alves, J. B., Gabani, F. L., Ferrari, R. A. P., Tacla, M. T. G. M., \& Link Junior, A. (2018) Sepse neonatal: mortalidade em município do sul do Brasil, 2000 a 2013. Rev Paul Pediatr. 36(2):132-140.

Barbosa, D. A. (2015) A importância da sistematização da assistência de enfermagem (SAE) em uma unidade de hemodiálise. Revista de Administração do Sul do Pará (REASP).

Bassi, A. A. P., \& Sampaio, V. R. E. (2018). Sepse: sinais, sintomas e cuidados de enfermagem. https://www.conic-semesp.org.br/anais/files/2017/trabalho1000025765.pdf.

Bittar, D. B., Pereira, L. V., \& Lemos, R. C. A. (2016). Sistematização da assistência de enfermagem ao paciente crítico: proposta de instrumento de coleta de dados. Texto Contexto Enferm, 15(4): 617-28.

Brasil. (2017). Agência Nacional de Vigilância Sanitária - ANVISA. Critério Diagnósticos de Infecção Associada à saúde - Neonatologia. Brasília: ANVISA, http://bvsms.saude.gov.br/bvs/publicacoes/criterios_diagnosticos_infeccoes_assistencia_saude_neonatologia.pdf.

Brito, C. G. A., \& Barcelos, V. M. (2017). Os desafios do enfermeiro para a realização da sistematização de Enfermagem na Atenção Básica. Revista Científica Multidisciplinar Núcleo do Conhecimento. 13. 129-143.

Dortas, A. R. F., Mello, D. M. da S., Bezerra, L. A., Lima, R. G., Neves, V. H. D., \& Aragão, J. A. (2019). Fatores de risco associados a sepse neonatal: Artigo de revisão. Revista Eletrônica Acervo Científico.

Freitas, C. B. S. de. Enfermagem relacionados ao processo de enfermagem. Dissertação (Mestrado) - Escola de Enfermagem da Universidade de São Paulo.

Hammad, M. S. Z. (2018). Meta-Analysis on Factors Influencing Early Onset Neonatal Sepsis. Scholar Journal of Applied Sciences and Research, 1(8), 20-22, 2018 .

Ludke, M. \& Andre, M. E. D. A. (2013). Pesquisas em educação: uma abordagem qualitativa. E.P.U.

Mota, E. C., Barbosa, D. A., Silveira, B. R. M., Rabelo, T. A., Silva, N. M., Silva, P. L. N. da, Ribeiro, J. L., Silva, C. S. de O., \& Gonçalves, R. P. F. (2014). Higienização das mãos: uma avaliação da adesão e da 'prática dos profissionais de saúde no controle das infecções hospitalares. Rev Epidemiol Control Infect. 2014,4(1):12-17.

Nascimento, V. F. do., \& Silva, R. C. R. (2014). da. Assistência de enfermagem ao recém-nascido pré-termo frente às possíveis intercorrências. Rev Enferm.

Oliveira, C. O. P. de., Souza, J. R. S., Machado, R. C., Feijão, A. R., \& Souza, N. L. (2016). Fatores de risco para sepse neonatal em unidade de terapia: estudo de evidência. Cogitare Enferm.

Procianoy R. S, \& Silveira R. C. (2020). The challenges of neonatal sepsis management. J Pediatr (Rio J). 2020,96(S1):80---6.

Reppetto, M. Â., \& Souza, M. F.de. (2015) Avaliação da realização e do registro da Sistematização da Assistência de Enfermagem (SAE) em um hospital universitário. Rev Bras Enferm.

Santos, A. P. de S., Silva, M. de L. C. da., Souza, N. L. de., Mota, G. M., \& França, D. F. de. (2014). Diagnóstico de enfermagem de recém-nascidos com sepse em uma Unidade de Terapia Intensiva Neonatal. Rev. Latino-Am. Enfermagem.

Silva, S. M. R., Motta, G. de C. P. da., Nunes, C. R., Schardosm, J. M., Cunha, M. L. C. (2015). Sepse neonatal tardia em recém-nascidos pré-termo com peso ao nascer inferior a $1.500 \mathrm{~g}$. Rev Gaúcha Enferm.

Silveira, R. de C., \& Procianoy, R. S. (2012). Uma revisão atual sobre sepse neonatal. Boletim Científico de Pediatria.

Souza, A., Amário, A., Covay, D., Veloso, L., \& Silveira, L., S. (2018) A. Conhecimento do enfermeiro sobre o choque séptico/ Nurses' knowledge on septic shock. Ciência, Cuidado e Saúde.

Souza, A. P. C., Garcia, R. A. de S., \& Silva Neto, M. F. da. (2020). Assistência de enfermagem em unidade de terapia intensiva nas alterações sistêmicas causadas pela sepse. Braz. J. Hea. Ver.

Souza, N. R., Costa, B. M. B., Carneiro, C. C. F, Barbosa, H. S. C., \& Santos, I. C. R. V. (2015). Sistematização da assistência de enfermagem: dificuldades referidas por enfermeiros de um hospital universitário. Rev enferm UFPE on line.

Viana, R. A. P. P., Machado, F. R., \& Souza, J. L. A. (2017). Sepse, um problema de saúde pública: a atuação e colaboração da enfermagem na rápida identificação e tratamento da doença. COREN-SP, 2017.

Tanure, M. C., \& Pinheiro, A. M. (2017). SAE Sistematização da Assistência de Enfermagem. Guanabara Koogan.

Terry, C. L., \& Weaver, A. (2013). Enfermagem em terapia intensiva. AMGH.

Westphalen, M. E. A., \& Carraro, T. E. (2011). Metodologia para a assistência de enfermagem: teorizações, modelos e subsídios para a prática. AB. 